\title{
As faces da subalternidade feminina no Portugal oitocentista em O Primo Basílio, de Eça de Queirós
}

\section{The faces of women subalternity in Portugal in nineteenth century on Cousin Bazilio, by Eça de Queiroz}

\section{Marcio Jean Fialho Sousa* \\ USP}

Resumo: O objetivo desse artigo é analisar as personagens Juliana e Joana, do romance $O$ Primo Basílio, de Eça de Queirós, fazendo uma comparação entre elas de modo que seja evidenciado como essas duas personagens, que possuem, basicamente, o mesmo status social, se relacionam entre si e como lidam com a condição subalterna a qual foram colocadas dentro de uma sociedade capitalista e patriarcal portuguesa, do século XIX, apresentada no romance. Vale salientar que, ainda que Juliana e Joana fossem empregadas de Luísa, o fato de Juliana ser "empregada de dentro" a faz se sentir, muitas vezes, superior a Joana durante a narrativa. Outro ponto a ser analisado é como ambas assumem ou não a condição de subalternidade e quais suas consequências para o desfecho do enredo. Como aporte teórico, foram utilizadas a perspectiva de subalternidade apresentada por Gayatri C. Spivak e estudos de João Medina acerca da presença feminina na obra de Eça de Queirós.

Palavras-chave: Subalternidade. Figura feminina. Eça de Queirós.

\begin{abstract}
The purpose of this article is to analyse Juliana and Joan characters from novel Cousin Bazilio, by Eca de Queiroz. It was making a comparison between them so that it is shown how these two characters, which have basically the same social status, relate themselves and how they deal with the subordinate status which were placed in a capitalist and patriarchal Portuguese society of the nineteenth century, presented in this novel. It is noteworthy that, although Juliana and Joan were employed Luisa, the fact Juliana be "employed within" makes her feel superior than Joan during the narrative. Another point to be considered is how both take on or not the subordinate condition and which are your consequences for the plot of the outcome. As theoretical framework, we used the prospect of subaltern Gayatri C. Spivak and studies about the female presence in the work of Eca de Queiroz presented by John Medina.
\end{abstract}

Keywords: Subalternity. Female presence. Eça de Queiroz.

A cada leitura feita das obras de Eça de Queirós um novo século XIX vai sendo construído para o leitor do século XXI. Especificidades do
* Doutorando e Mestre em Letras (Literatura Portuguesa) pela FFLCH-DLCV da Universidade de São Paulo - USP. Atualmente, Professor da Rede Estadual de Ensino da SEE/SP. É pesquisador do Grupo Eça-USP.

E-mail: pavlovfialho@ ig.com.br 
cotidiano português vão sendo reveladas e uma nova caracterização vai sendo desvendada. Nesse sentido, Eça de Queirós, como bom observador de seu tempo, penetrou ao fundo os problemas sociais vividos em seu tempo, ora como crítico de costumes ora como observador. E foi assumindo esse duplo olhar que o autor de Os Maias eternizou a mulher finissecular em sua obra.

Nesses termos, temos que concordar com João Medina quando afirma que “Eça de Queiroz é um dos primeiros romancistas portugueses que vê realmente a Mulher, não a mulher abstrata e intemporal do eterno feminino mas a mulher portuguesa do seu tempo” (MEDINA, 2000, p. 77), assumindo vários papéis sociais. Em sua obra, Eça apresenta a figura feminina em todos os seus pormenores, assim destaca João Medina:

A mulher burguesa, vítima da criadagem que rouba ou detesta, do coro que a rodeia - no caso de Luísa, esse microcosmo que é a rua da Patriarcal Queimada, entre a Praça da Alegria e a praça do Príncipe Real, com um coro de olhos indiscretamente ávidos de mexerico e coscuvilhice que seguem todos os seus movimentos, lambendo a rua, nesse coração mesmo da vivência citadina da Lisboa fontista, a mulher vestida de maneira artificial e sufocante do nosso oitocentos, ou seja, entre o espartilho que a aperta e a cuia que lhe dá um ar falso. (MEDINA, 2000, p. 77)

Nesse estudo, João Medina é assertivo ao demonstrar o quanto a mulher se faz presente na pena queirosiana, porém deixa de dar uma especial atenção à mulher serviçal, a encarregada por recolher as águas sujas depois que suas patroas se deliciaram em banhos cheios de perfumes, faltou elevar aquela que está escondida nas cozinhas e no quarto dos engomados. Quando se refere a essas mulheres específicas, João Medina apenas afirma que eram mulheres que faziam de suas patroas as vítimas de suas crueldades.

Não há dúvidas, de que a mulher burguesa na obra queirosiana tem certo destaque que a distingue das outras mulheres da sociedade, por outro lado, na medida em que as suas dificuldades cotidianas vão sendo apresentadas, vê-se que não é só a mulher burguesa que se torna vitimada, mas todas as mulheres retratadas em seus romances assumem um papel subalterno dentro dessa sociedade portuguesa oitocentista, independente do status social a qual pertencem.

O conceito de subalterno está sendo aqui empregado a partir dos estudos propostos por Gayatri C. Spivak, apresentado no livro intitulado Can the Subaltern Speak?. Nesse trabalho, Spivak define como subalterno aquele que "não pode ocupar uma categoria monolítica e indiferenciada, pois esse sujeito é irredutivelmente heterogêneo” (2012, p. 13), ou seja, o subalterno não pertence a um grupo social, seu lugar não se define por padrões, são heterogêneos porque não se organizam entre si. Sendo assim, não pertencem a um grupo privilegiado (aqueles que possuem padrões), não se adequam, não possuem representatividade, são aqueles sujeitos cujas vozes não podem ser ouvidas. 
Subalterno será também, segundo Spivak, sinônimo de proletariado, serão aqueles que pertencem "às camadas mais baixas da sociedade construída pelos modos específicos de exclusão dos mercados, da representação política e legal, e da possibilidade de se tornarem membros plenos no estrato social dominante" (SPIVAK, 2012, p. 14). ${ }^{1}$

Essas duas posições em relação a mulher são claramente vistas nas obras de Eça de Queirós, não há dúvidas disso. Porém, em virtude do espaço a que se destina esse artigo, e dos objetivos ora apresentados, será avaliada essa presença feminina apenas em $O$ Primo Basílio, romance publicado por Eça de Queirós, em 1878, após a publicação de O crime do Padre Amaro, que teve sua primeira edição em 1875.

Partindo desses conceitos e passando para o estudo de O Primo Basílio, parece ser de conhecimento geral que este é um romance que tem como tema central o adultério, porém não se entrará ao mérito desse estudo. Entretanto, ainda que não analisemos como se deu esse disparate, a análise das figuras de Joana e Juliana permearão, de certo modo, esse ocorrido já que elas testemunharam todo o desenrolar dos fatos por estarem sempre em casa servindo Luísa.

Dentre as personagens de segunda ordem que aparecem no enredo, aqui será dado especial atenção à figura de Joana, a cozinheira, fazendo contraponto com Juliana, a empregada de dentro. O objetivo dessa comparação é analisar como essas duas personagens, que possuem, basicamente, o mesmo status social, se relacionam entre si e como lidam com a condição subalterna a qual foram colocadas, histórica e geograficamente marcada, dentro de uma sociedade capitalista e patriarcal portuguesa, do século XIX.

O primeiro ponto que vale analisar é a posição social que cada uma das empregadas de Luísa assume no enredo. Ainda que ambas fossem empregadas da casa, também entre elas havia certa distinção categórica. Uma era empregada de dentro, a outra cozinheira, a saber Joana e Juliana, respectivamente.

Como cozinheira, Joana não interagia com as visitas da casa, nem servia diretamente a seus patrões. Enquanto Juliana, na função de empregada de dentro, ficava encarregada dessas funções mais sociais, o que não tiraria, porém, sua responsabilidade de ter que tirar as “águas sujas”, depois que seus patrões tomassem banho e de engomar roupas. Essa diferença de função era o suficiente para que o relacionamento entre elas também fosse desenvolvido em meio a desigualdades. Um exemplo disso se dá na cena em que numa certa noite, sem conseguirem dormir por causa do calor que fazia, Joana e Juliana começam a conversar, cada uma do seu próprio quarto, que era um ao lado do outro:

- Já se deitou, Sra. Joana, já. Está hoje com os azeites. Falta-lhe homem! Joana, às voltas, fazia ranger as madeiras velhas da cama. Não podia dormir! Abafava-se!
${ }^{1}$ Tradução livre feita por Sandra Regina Goulart Almeida, apresentada no Prefácio do livro Pode o subalterno falar?, edição publicada no Brasil, usada como referência nesse estudo. 
Uf!

- Ai! E aqui! - exclamou Juliana.

Abriu o postigo que dava para os telhados, para deixar arejar; calçou as chinelas de tapete, e foi ao quarto de Joana. Mas não entrou, ficou à porta; era criada de dentro, evitava familiaridades. (Grifo meu. QUEIROZ, 1994, p. 72)

Como se lê, não havia cumplicidade entre Juliana e Joana, não havia proximidade, “evitava familiaridades”, diz o narrador. Os locais sociais as quais tinham sido colocadas eram vivenciados e mesmo endossados também entre elas mesmas. Buscando respostas dentro do texto para os distintos comportamentos das empregadas de Luísa, é possível encontrar alguns elementos que ajudam a compreender um pouco dessas mulheres responsáveis por realizar os mimos de sua senhora.

Juliana trabalhava como empregada doméstica há vinte anos, era uma mulher rancorosa, vingativa, invejosa e muito dissimulada. Até dos amores de Joana, Juliana tinha inveja. Quanto às patroas as quais tinha servido, Juliana classifica-as

[...] na mesma palavra - uma récua! E detestava as boas pelos vexames que sofrera das más. A ama era para ela o inimigo, o tirano. Tinha visto morrer duas - e de cada vez sentira, sem saber porquê, um vago alívio, como se uma porção do vasto peso, que a sufocava na vida, se tivesse desprendido e evaporado! (QUEIROZ, 1994, p. 78)

O narrador tenta justificar essas características de Juliana, assim como seu mal humor, ao apresentar aspectos da vida que ela tinha levado durante esse tempo:

[...] mudava de amos, mas não mudava de sorte. Vinte anos a dormir em cacifos, a levantar-se de madrugada, a comer os restos, a vestir trapos velhos, a sofrer os repelões das crianças e as más palavras das senhoras, a fazer despejos, a ir para o hospital quando vinha a doença, a esfalfar-se quando voltava a saúde! (QUEIROZ, 1994, p. 75)

Em outro trecho do livro, o narrador nos apresenta ainda a sofrida infância e tristes anos escolares de Juliana, justificando de forma determinista o porquê de suas rabugices (QUEIROZ, 1994, p. 75).

Outro episódio que marca negativamente a vida de Juliana foi aquele em que ela se dedicara durante muito tempo a cuidar da tia de Jorge, Virgínia Lemos. Virgínia não tinha herdeiros diretos e todos sabiam que sua saúde era muito debilitada, logo, Juliana, sempre incentivada por tia Vitória, começa a acreditar ainda mais que agora poderia ficar com a riqueza da senhora, assim que sua morte chegasse, afinal, nem mesmo Jorge ia visitá-la, para isso seguia todos os conselhos de Vitória. Assim dizia tia Vitória: “- Tu tratas a velha, apaparica-a, que ela o que quer é uma enfermeira que a sofra. É rica, 
não é nada apegada ao dinheiro; é capaz de te deixar uma independência!” (QUEIROZ, 1994, p. 79).

Mas não foi o que aconteceu. Virgínia morre e nada deixa a Juliana, destina tudo ao sobrinho Jorge. Depois disso, vê-se na obrigação de se dedicar a Luísa, por falta de opção de uma vida melhor, mas eis que quando já não tinha mais esperança de uma vida melhor, aparece um velho primo de Luísa, Basílio, que, nos anos de juventude, havia sido namorado de Luísa e começa a visitá-la com frequência enquanto Jorge, nesse momento, passava uma temporada fora de casa atendendo a compromissos profissionais. Juliana começa então a desconfiar de tantas visitas e é a partir disso que a empregada de dentro começa a arquitetar um plano que a levaria à fortuna.

Com esse contexto, pode-se verificar o quanto Juliana vive apenas impulsionada pelo interesse, não tem nada nem ninguém, pensa na sua própria velhice e na miséria de sua vida. Por isso, todas as suas ações acabam se resumindo em troca de favores:

Juliana lisonjeava sempre a cozinheira; dependia dela; Joana dava-lhe caldinhos às horas de debilidade, ou, quando ela estava mais adoentada, fazia-lhe um bife às escondidas da senhora. (Grifo nosso. QUEIROZ,1994, p. 61).

Sobre Joana, o narrador dá conta de que

Era uma rapariga muito forte, com peitos de ama, o cabelo como azeviche, todo lustroso do óleo de amêndoas doces. Tinha testa curta de plebeia teimosa. E as sobrancelhas cerradas faziam-lhe parecer o olhar mais negro. (QUEIROZ, 1994, p. 60)

Além disso, tinha certo desprendimento de bens materiais, não se preocupava em comprar roupas novas ou juntar pequenas riquezas, mesmo passando por necessidades financeiras, preferia doar seu dinheiro ao amante a comprar "camisas” de que precisava (QUEIROZ, 1994, p. 73), junto a isso, tinha também grande preocupação com a própria saúde. Diferente de Juliana que preferia gastar todo seu dinheiro comprando botinas a cuidar de sua saúde debilitada.

Como se nota, as perspectivas de vida de Joana eram completamente diferentes das de Juliana, ainda que ambas tivessem as mesmas condições precárias de vida. Joana arruma tempo para cultivar amores enquanto Juliana vivia para se lamentar, mas o que ainda dava a ela alguns estímulos era pensar que um dia sua sorte poderia ser diferente e nisso ela se apegava e acreditava, sendo inclusive incentivada por tia Vitória, uma velha amiga que servia para escutar suas lamúrias e, acima de tudo, para aconselhar Juliana.

Enfim, ainda que tanto Joana quanto Juliana pertencessem a camada subalterna da sociedade, nota-se que o modo como cada uma acaba 
conduzindo suas vidas é muito antagônico. Joana não pensava no futuro, vivia o momento presente, vivia seus amores, fazia "suas festinhas" quando se encontrava sozinha na casa. Juliana, por seu turno, vivia para o devir material, preocupava-se apenas com o presente para preparar o futuro: se esse fosse bom, teria o pão para comer na velhice, se assim não fosse, seria jogada na rua, como, em geral, acontecia com as empregadas idosas ou doentes. Nessa relação social ninguém as representava, ninguém as defendia, suas vozes não eram ouvidas a não ser entre si mesmas.

Essas diferenças de interesse ficam claras na única cena em que ambas desenvolvem um diálogo longo, na ocasião, Joana se coçava por causa de percevejos que tinha no quarto:

- Ai! É um inferno! - disse com lástima Juliana. - Eu só adormeço com o dia. Mas ainda eu agora reparo... Vossemecê tem São Pedro à cabeceira. É devoção?

- É o santo do meu rapaz - disse a outra. Sentou-se na cama. Ouf! E então tinha estado com uma sede!...

Saltou para o chão, com passadas rijas que faziam tremer o soalho, foi ao jarro, pô-lo à boca, bebeu uma tarraçada. A camisa justa, feita de pouca fazenda, mostrava as formas rijas e valentes.

- Pois eu fui ao médico - disse Juliana. E com um grande suspiro: - Ai! Isto só Deus, Sra Joana! Isto só Deus!

Mas por que não se resolvia a Juliana a ir à mulher de virtude? Era saúde certa. Morava ao Paço dos Negros; tinha orações e unguentos para tudo. Levava meia moeda pelo preparo...

- Que isso são humores, Sra Juliana. O que vossemecê tem são humores.

Juliana tinha dado dois passos para dentro do quarto. Quando se tratava de doenças, de remédios, tornava-se mais familiar.

- Eu já me tenho lembrado... eu já me tenho me lembrado de ir à mulher. Mas, meia moeda!

E fico a olhar, tristemente, refletindo.

- É o que eu tenho junto para umas botinas de gáspea!

Era um vício, as botinas! [...]

Joana censurou-a.

- Ai! eu, em se tratando do corpo, do interior, que o diabo leve os arrebiques! (QUEIROZ, 1994, p. 73)

O posicionamento de Eça de Queirós presente nesse trecho, e em outros de seus romances, em relação às mulheres é também, de certa forma, herança de muitas de suas leituras, por exemplo, da obra de Pierre-Joseph Proudhon, principalmente no que tange às personagens femininas protagonistas. Segundo esse filósofo, a mulher é uma figura subalterna e, por isso, suas funções devem ser distintas das dos homens, para superá-los era necessário, porém, que tivesse a ajuda do próprio homem, pois sozinha isso não seria possível (MATOS, 1988, p. 76). 
Sendo assim, o local que as domésticas assumem nesse romance é o espaço subalterno da subalternidade das mulheres. Isso porque se a mulher, subalterna por natureza, segundo Proudhon, ainda poderia vir a contar com a voz masculina que lhe daria o sobrenome e um lugar na sociedade, Joana e Juliana, no enredo, não podem contar nem com isso, já que Joana tem um namorado às escondidas e com isso já se mostrava satisfeita. $\mathrm{O}$ casamento nem é mencionado em seu discurso, tampouco nas palavras do narrador e Juliana, por seu turno, contava apenas com a companhia de tia Vitória que também nem era uma senhora da sociedade.

Sendo assim, as domésticas desse romance assumem um não-lugar no mundo feminino português do século XIX, pois se em Proudhon a mulher serviria a uma dicotomia: cortesã ou dona de casa, Joana e Juliana não assumem nem uma posição nem outra. Talvez Joana, por causa de seus encontros às escondidas com Pedro, poderia ser vista como cortesã, hipótese refutável, mas Juliana, nem mesmo a um namorico havia se dado:

O único homem que a olhara com desejo tinha sido um criado de cavalariça, atarracado e imundo, de aspecto facínora: a sua magreza, a sua cuia, o seu ar domingueiro tinham excitado o bruto. Fitava-a com um ar de buldogue. Causara-lhe horror, - mas vaidade. E o primeiro homem por quem ela sentira, um criado bonito e alourado, rira-se dela, pusera-lhe o nome de Isca Seca! Não contou mais com os homens, por despeito, por desconfiança de si mesma. (QUEIROZ, 1994, p. 79)

Mas Juliana não aceita esse lugar destinado a ela nesse romance e a única maneira, na sua visão, para ascender socialmente dentro dessa sociedade seria encontrando ou descobrindo algo que incriminasse Luísa, sua patroa. É assim que Juliana, depois de tomar posse das cartas que provariam o caso de adultério entre Luísa e Basílio, vendo-se com a oportunidade de ganhar o dinheiro que seria o sustendo para a sua velhice e aconselhada por tia Vitória, chantageia Luísa pedindo que essa lhe pagasse pelas cartas a quantia de 600 mil réis, dinheiro que Luísa não teria nem que vendesse suas joias todas.

Durante certo tempo, Juliana consegue manter suas chantagens diante da patroa, mas quando Luísa, não aguentando mais tanta humilhação nem o serviço pesado a qual não estava acostumada em sua vida de burguesa, toma coragem e confidencia a Sebastião, amigo da família, seu romance e fala sobre as cartas roubadas, este assume para si o compromisso de recuperar as cartas, Juliana, que já tinha a saúde debilitada, indignada por não ter conseguido levar a cabo seu projeto de aposentadoria morre depois de entregar tudo a Sebastião.

Joana, por seu turno, ainda que humilhada, até mesmo por Juliana, como já demonstrado nessa análise, manteve-se sempre esperançosa e fiel à patroa até os momentos finais da vida de Luísa, que acaba morrendo de desgosto no final do romance. 
Dessa forma, às domésticas de Luísa está reservado o lugar subalterno apresentado por Spivak. Elas são homogêneas em suas posições sociais, porém heterogêneas em suas relações entre si, no espaço a elas destinado. Estão fora do grupo privilegiado da sociedade e, por isso, não possuem representatividade, não são representadas por outrem nem se fazem valer de suas vozes, a única que tenta ser ouvida de alguma forma, é Juliana que, utilizando-se do único recurso que possui, vale-se de estratégias de chantagem frente à representante da sociedade burguesa feminina.

Enfim, pensar sobre o lugar dessas mulheres fadadas ao serviço as suas patroas, inseridas na sociedade portuguesa oitocentista, implica vê-las como figurantes e, por isso, apagá-las, na maioria das vezes, da história social. Essa relação foi aqui evidenciada na medida em que a presença dessas mulheres simplesmente é ignorada pelas personagens principais do romance e, até mesmo, pelo leitor. Por outro lado, o desfecho do romance necessita dessas duas personagens para que o final chegue ao esperado pelo autor, isso implica dizer que, o final é trágico para as mulheres que de alguma forma subverteram a expectativa do comportamento social dentro desse contexto oitocentista português.

\section{Referências}

QUEIROZ, Eça de. O Primo Basílio. São Paulo: FTD, 1994.

SPIVAK, Gayatri Chakravorty. Pode o subalterno falar? Belo Horizonte: Editora UFMG, 2012.

MATOS, A. Campos. Dicionário de Eça de Queirós. 2a ed. Lisboa: Editorial Caminho, 1988.

MEDINA, João. Reler Eça de Queiroz - Das Farpas aos Maias. Lisboa: Livros Horizontes, 2000.

Recebido em novembro/2015

Aceito em dezembro/2015 